\title{
Response of Parents Towards Parental Class as A Collaborative Model in Physical Education
}

\author{
Slamet Santoso ${ }^{1}$, Tandiyo Rahayu ${ }^{2}$, Tjetjep Rohendi Rohidi ${ }^{3}$, Mugiyo Hartono ${ }^{4}$ \\ \{ssantoso111285@gmail.com ${ }^{1}$, tandiyorahayu@mail.unnes.ac.id ${ }^{2}$, mugiyohartono@mail.unnes.ac.id ${ }^{4}$ \} \\ Universitas Tunas Pembangunan Surakarta, Surakarta, Indonesia ${ }^{1}$ \\ Universitas Negeri Semarang, Semarang, Indonesia ${ }^{2,3,4}$
}

\begin{abstract}
This study aims to describe the response of parents towards parenting class as a collaborative model in physical education involving teachers, parents and the community by sharing responsibilities, duties and involvement according to their respective roles. The results of the pilot study involved 6 primary schools in rural and urban areas for 12 months. This type of research is mix methods. The data were collected through questionnaire to 166 participants. Then, the data were analyzed by a sequential explanatory strategy. The results showed that parents' responses to the collaboration model in the primary schools regarded as 'good' with the overall-average score of $81.97 \%$. Based on the results of the interview, parents could experience the benefits of the program such as knowledge enhancement, insight and parenting patterns as well as medium of communication between parents and teachers related to children's learning progress and character building.
\end{abstract}

Keywords: Response of parents, parental class, physical education.

\section{Introduction}

In terms of education, parents must have their way of parenting, It may vary one another as each has a diverse background; among others are level of education, job, socio-culture, and the surrounding environment. This diversity can make their children's growth and capacity development (such as cognitive, affective, and psychomotor) differently. It is hence, cultivating the understanding of their approach of educating and parenting their children is necessary to improve their quality. Parents who have certain quality will be able to nurture and educate their children as best as possible so that they can increase the capacity of theirs.

The roles and contributions of parents, families, and community leaders have been regulated in the National Education System Law Number 20 the Year 2003 Article 7 paragraph 1 that reads "Parents and the community have the right to participate in planning, implementing, monitoring and evaluating the educational programs". Education is our shared duty and responsibility comprising family, community, and government.

Partnerships between families, schools, and communities are built to create an educationalcharactered ecosystem, a culture of healthy living and exercise and to improve learning achievement in terms of cognitive, affective, and psychomotor [1]. The family as the very first educational unit is expected to increase the growth and development of their children according to their level so that they become an independent, intelligent, and productive personality. Family (in this case parents) play several important roles and contribute to providing the basics of 
education such as religion, personality, character, individual-socialistic characters, norms, regulations, instilling a healthy lifestyle, and exercising.

The implementation of good and qualified education requires a suitable, planned, programmed, and sustainable relationship as well as collaboration between teachers and parents and the community as a form of sound partnership and synergy. According to Palupi Raraswati [2], the partnership and collaboration between the school and the family is a positive and important thing because 1) parents are the first educators, but in fact, the majority of parents only leave over the system to the school, 2 ) schools act a role as a family partner in implementing the qualified, programmed and more systematic education, 3) the complex needs of the children who cannot fully be fulfilled by schools and families, 4) the collaboration between parents and teachers is a compulsory in education, 5) schools are obliged to encourage partnerships, collaboration and involvement with parents to cultivate and improve the quality of education itself.

Hence, to improve the quality of the parents in terms of education and parenting for their children, it is necessary to have a forum that can accommodate and facilitate parents and teachers, and stakeholders to be able to complement each other and harmoniously join hand in hand through the parent class in physical education. According to the General Directorate of Early Childhood Education and Community Education [3], the parental class is a forum for parents that can be used to unite parents, teachers, and the community into a single unit in a classroom to improve knowledge, insight, mindset and parental patterns through effective communication expecting that they can share their duties, roles, and involvements in the education process to create good collaboration between stakeholders in realizing the goals of national education. The communication and interaction between the school (teachers) and family (parents) have a positive impact on children such as being diligent in doing homework, behaving well, and being more active, and elevating social aspects, Kraft, MA, and Dougherty, S.M [4] [5].

Currently, there are several school programs such as the parent association that has tried to involve parents and stakeholders, but they have not yet related to physical education. The parental involvement program in the education process that has been running so far has not been effective and efficient due to unclear, unsustainable school programs, lack of parental awareness, and varied parental mindsets.

\section{Method}

This is research on parents' responses to parenting classes as a collaborative model in physical education. The subjects of this study were the parents of elementary school students in Magelang Regency in 2019 (166 participants). This is mixed-methods research combining qualitative and quantitative approaches, Sugiyono [6]. The utilized research design is sequential explanatory, in which quantitative data is first collected and analyzed, before the qualitative data. According to Creswell [7], qualitative data findings can be used to contextualize the quantitative data.

The following are the stages of data analysis used in this study:

Quantitative Data Analysis. The quantitative data were collected using a rating scale questionnaire with 25 statement items about the responses of parents towards parental class as a collaboration model in physical education which includes; 1) responsibility 2) tasks, 3) involvement 4) role 5) collaboration between parents and teachers and the education 
community. The result of the questionnaire was then identified the mean value before it is analyzed in a descriptive percentage form. The data obtained through a questionnaire refers to the Likert scale parameter. The scores are determined as follows: SA: Strongly Agree (4); A: Agree (3); D: Disagree (2); SD: Strongly Disagree (1).

Qualitative Data Analysis. The interview data collection (qualitative) is carried out when the questionnaire data (quantitative) have been obtained. The qualitative data were obtained by interviewing 18 parents who were class administrators (chairperson, secretary, and treasurer) from 6 elementary schools, then the data were reduced (selecting and determining the important parts), then concluded.

\section{Result and discussion}

The response of parents in responding to the existence of this parental class program is of course diverse and vary. In details, based on the data of the rating scale questionnaire with 25 statement items regarding the responses of parents to the collaboration of model of teachers, parents, and society to 166 participants as in table 1 . as follows:

Table 1. The response of parents towards the parental class as a collaborative model in physical education

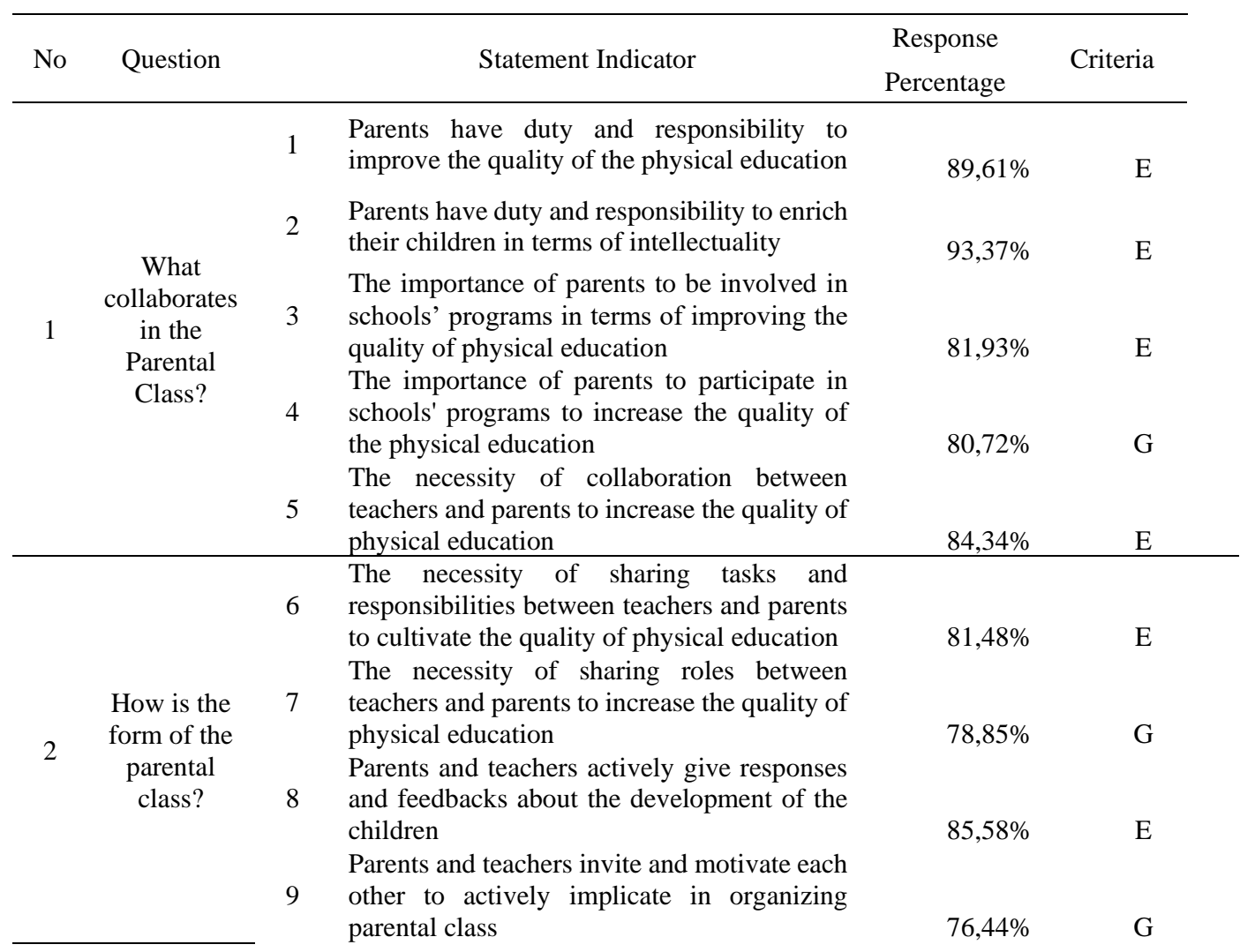


10 The necessity of parent organization accommodated in the form of parental class

11 Parents can create a joyful, secure, and comfortable learning atmosphere

Parents and teachers are active in monitoring

12 the attitude, social interaction, and development of children

$89,90 \% \quad \mathrm{E}$

13 Parents and teachers support the activity of the parental class program

$78,37 \% \quad G$

14 Parents, teachers, community, and children can do an exercise together

$76,92 \%$

G

15 Teacher as an initiator in organizing parental class program

$80,12 \% \quad G$

16 Teacher as a mediator in organizing parental class program

17 Teacher as a motivator in arranging the parental class program

18 Teacher as a mediator in arranging the parental class program

Who are

19 Teacher as a controller in organizing parental class program

The teacher is directly implicated in the in the

Parental

Class? formation of parental class organizer formation of the parental class program arrangement

The parent is directly implicated in the class management of parental class

23 materials per the needs of the parental class program

The education community can be an

The necessity of community education to be involved in the parental class program 
Table 2. Recapitulation of parents' responses

\begin{tabular}{|c|c|c|c|c|c|c|c|}
\hline \multirow{2}{*}{$\begin{array}{l}\text { Percentage } \\
\text { interval }\end{array}$} & \multirow{2}{*}{ Criteria } & \multicolumn{2}{|c|}{$\begin{array}{l}\text { What } \\
\text { is collaborated }\end{array}$} & \multicolumn{2}{|c|}{$\begin{array}{l}\text { How is the form of } \\
\text { the collaboration }\end{array}$} & \multicolumn{2}{|c|}{$\begin{array}{l}\text { Who is the element } \\
\text { of the collaboration }\end{array}$} \\
\hline & & Frequency & $\%$ & Frequency & $\begin{array}{l}\text { Percent } \\
\text { age }\end{array}$ & $\begin{array}{c}\text { Frequen } \\
\text { cy }\end{array}$ & $\%$ \\
\hline $\begin{array}{c}81,26 \%- \\
100 \%\end{array}$ & Excellent & 100 & $60 \%$ & 96 & $58 \%$ & 28 & $17 \%$ \\
\hline $\begin{array}{l}62,51 \%- \\
81,25 \%\end{array}$ & Good & 64 & $39 \%$ & 70 & $42 \%$ & 132 & $80 \%$ \\
\hline $\begin{array}{c}43,76 \%- \\
62,50 \%\end{array}$ & Fair & 2 & $1 \%$ & 0 & $0 \%$ & 5 & $3 \%$ \\
\hline $\begin{array}{c}25 \%- \\
43,75 \%\end{array}$ & Poor & 0 & $0 \%$ & 0 & $0 \%$ & 1 & $1 \%$ \\
\hline \multicolumn{2}{|c|}{ Total } & 166 & $100 \%$ & 166 & $100 \%$ & 166 & $100 \%$ \\
\hline \multicolumn{2}{|c|}{ Overall Average } & \multicolumn{2}{|c|}{$85,99 \%$} & \multicolumn{2}{|c|}{$83,38 \%$} & \multicolumn{2}{|c|}{$78,98 \%$} \\
\hline \multicolumn{2}{|c|}{ Criteria } & \multicolumn{2}{|c|}{ Excellent } & \multicolumn{2}{|c|}{ Excellent } & \multicolumn{2}{|c|}{ Good } \\
\hline
\end{tabular}

Based on data shown in Table 1 and table 2 the response of parents to the collaborative model of teachers, parents, and community in terms of sharing tasks, responsibilities, involvement, and roles of each other is considered as Excellent with an overall average of $81.97 \%$. In detail, this consists of 1) parents' response to the collaborated matters is $85.99 \%(\mathrm{E})$, 2 ) the response of parents related to how the form of collaboration is $83.38 \%(\mathrm{E}), 3)$ the response of parents related to the personnel involved in the collaboration is $78.98 \%(\mathrm{G})$.

Furthermore, based on the results of the open interview with 10 question items to class administrators consisting of the chairman, secretary, and treasurer from each school, totaling 18 people, generally stated that essentially the participants strongly agreed with the existence of the parental class. This program allows parents to be directly and actively involved in efforts to improve the quality of education and to shape the character of their children enhanced. The following is one of the excerpts of the interview to one of the parental class administrators: $\{$ “..... essentially, we strongly agree with the parental class program because with this parental class, there are mutual collaboration and cooperation between parents and teachers. Therefore, concerning physical education, in particular, it is very very helpful. With this parent class, $M r$. Slamet, it turns out that it is also able to increase parents' awareness and their involvement even more real and clear, not only in the physical education but also related to UKS (School Health Unit) and so on. This parental class can build good communication between the school and parents so that everything related to education, sports, character, and children's development can be monitored together and we strengthen each other. 
In addition to this, it turns out that, Mr. Slamet, with the existence of this parent class, can really increase the level of discipline of the child, and we, as parents, often meet with other parents and the school administrators, so that there is positive communication, especially when we get guidance from the resource person of the parenting activities..."?

The results of the interview indicate that the collaborative model through the parental class is well accepted and responded to. The enthusiasm of the parents in participating in this parental class activity is also immense because they have experienced several benefits such as:

1. The ability to raise awareness for parents to be more caring and active in accompanying their children.

2. Increasing the knowledge, insight, and ability of parents in educating and caring for children at home.

3. Sharing knowledge, insights, and experiences with fellow parents.

4. Increasing their role, participation, and contribution in collaboration between classroom teachers, physical education teachers, parents, and the community.

5. Establishing a system and model of parent class that is suitable for the needs.

6. Empowering parents to play a role and participate actively in implementing parent class programs to improve the quality of physical education, sports, and health at the primary school level.

7. Knowing and understanding physical education materials as the subject of the parental class program.

8. Knowing and understanding physical education materials taught at the primary school level according to the child's level.

9. Building partnerships and collaborating with interested people and can contribute to the implementation of the parental class program.

10. Equipping parents about good and correct parenting patterns for the child's future.

11. Building effective communication between physical education teachers, school principals, parents, and the community

12. The harmonization of education that children receive at school and home.

13. Supporting from parents to children is increasingly clear and programmed.

14. The ability to do sports together.

15. Parents' attention to children will increase and children will respect their parents more.

16. The formation of a better children's character.

17. The ability to organize and manage time for school, play, study and sports, and other activities.

18. The ability to improve discipline and student attendance.

19. To be more aware of how important it is to study with anyone, anywhere.

20. Understanding the background, social, cultural, economic, and parenting patterns in the family.

21. The ability to respect and understand the differences between parents.

22. The ability to share information between teachers and parents about learning outcomes, growth, and development of their children.

23. There is good communication between teachers and parents.

24. Minimizing the gap between teachers and parents.

25. Learning media and classroom facilities are becoming more complete and better 


\section{Conclusion}

In general, the response of parents to the collaborative model of teachers, parents, and the community in physical education in elementary schools is classified as good with an overall average of $81.97 \%$ The enthusiasm of the parents in joining the parental class is also enormous because they have experienced numerous benefits. This form of collaboration in the parental class is a form of interaction, discussion, compromise, cooperation, sharing of roles, duties, and responsibilities related to students, parents, teachers, or other stakeholders. We need to know together that education is our common duty and responsibility, therefore to create a qualified education we must unite, synergize and collaborate. This collaboration involves several elements of school members and stakeholders such as; 1) principal, 2) class teachers and physical education teachers, 3) parents, 4) the education community (school committee, school supervisor, instructor, education practitioner, etc.).

\section{References}

[1] General Directorate of Early Childhood Education and Community Education. 2015. Roadmap of Family Education Revised Edition. Jakarta: Ministry of Education and Culture

[2] Palupi Raraswati. The policy of Family Guiding/Coaching. Jakarta. Ministry of Education and Culture. 2016.

[3] Ministry of Education and Culture. Implementation of Parents' Class. Jakarta: Ministry of Education and Culture. 2017.

[4] Kraft, M. A., \& Dougherty, S. M. The effect of teacher-family communication on student engagement: Evidence from a randomized field experiment. Journal of Research on Educational Effectiveness. 2013; 6(3): 199-222.

[5] National Education Department. Indonesian Law No. 20 the Year 2003 about National Education System. Jakarta: National Education Department. 2003.

[6] Sugiyono. Kuantitatif, Qualitative, and Mix Research Methods. Bandung: Alfabeta. 2013.

[7] Creswell, J. W. Steps in conducting a scholarly mixed methods study. DBER Speaker series. University of Nebraska. 2013 